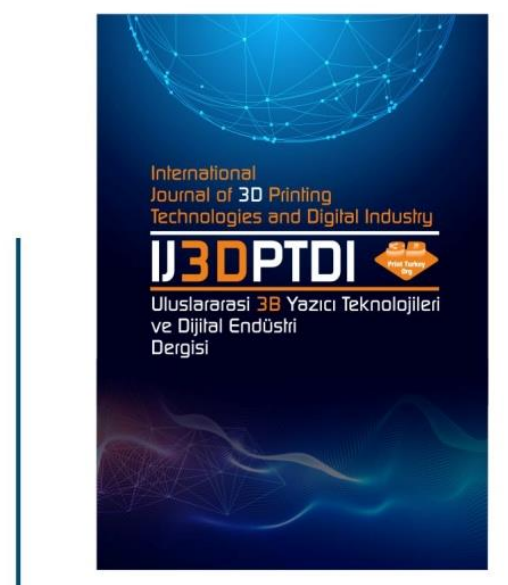

ULUSLARARASI 3B YAZICI TEKNOLOJILERI

VE DIJITAL ENDÜSTRI DERGISI

INTERNATIONAL JOURNAL QF 30 PRINTING TECHNOLOGIES AND DIGITAL INDUSTRY

IS5N:2602-3350 [Online]

URL: https://dergipark.org.tr/ij3dptdi

\title{
IN-SITU SYNTHESIS OF 3D-PRINTED MAGNETIC NANOPARTICLES EMBEDDED PHOTOPOLYMERS
}

Yazarlar (Authors): Mehmet Fahri SARAC (1)*

Bu makaleye şu şekilde atıfta bulunabilirsiniz (To cite to this article): Sarac M.F., "InSitu Synthesis of 3D-Printed Magnetic Nanoparticles Embedded Photopolymers" Int. J. of 3D Printing Tech. Dig. Ind., 5(2): 164-170, (2021). 


\title{
IN-SITU SYNTHESIS OF 3D-PRINTED MAGNETIC NANOPARTICLES EMBEDDED PHOTOPOLYMERS
}

\author{
Mehmet Fahri SARAC ${ }^{(i D} *$

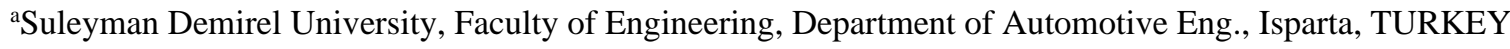 \\ *Correponding Author: fahrisarac@sdu.edu.tr
}

(Received: 16.06.2021; Revised: 07.07.2021; Accepted: 06.08.2021)

\begin{abstract}
In order to enhance magnetic and thermal properties of polymeric structures in 3D (three-dimensional) form, stereolithography technique is an alternative way to in-situ synthesize magnetic nanoparticles such as iron, cobalt and nickel in photocurable resin during laser photopolymerization for magnetic micromachines. By using different types of magnetic nanoparticles in the resin, the formed structure exhibits different mechanical, thermal and magnetic behaviors.

In this study, magnetic nanoparticles were synthesized by laser irradiation to investigate the effects of the magnetic nanoparticles in 3D structure. Under constant metal salt amount and forming layer thickness, morphological, characterization, mechanical, thermal and magnetic properties were conducted by scanning electron microscope (SEM), transmission electron microscope (TEM), tensile test, thermal gravimetric analysis (TGA), differential scanning calorimetry (DSC) and vibrating sample magnetometer (VSM), respectively. As a result, it observed that the magnetic properties of iron-based polymeric structures show higher saturation magnetization $(0.0145 \mathrm{emu} / \mathrm{gr})$ while thermal stability remains low for other magnetic embedded polymer samples. In the presence of magnetic nanoparticles, its mechanical strength decreased from $14 \mathrm{MPa}$ to $5 \mathrm{MPa}$ for all experiments against pure 3D resin, as well as it leads to more fragile structures. Finally, for each sample, singular magnetic nanoparticles were formed in the polymer matrix and verified that nanoparticles are completely reduced.
\end{abstract}

Keywords: iron, nickel, cobalt, stereolithography, photocurable resin, nanoparticle

\section{INTRODUCTION}

Considering the technological developments in recent years, 3D printers, which have been increasingly demanded with the increase of the performance / price relationship, have attracted the attention of many researchers and entrepreneurs in the last two decades [1]. Unlike filament-based polymers, the ability of liquid resin-based 3D polymeric structures to produce high precision and complex geometries distinguishes them from other additive manufacturing technologies [2,3]. These liquid-based resins are called acrylate-based epoxy resins or photo-sensitive polymers. Photocurable resins can be produced depending on various mechanical properties such as colored, transparent or dental applications. Today, many of the parts produced with a 3D printer are used as conceptual prototypes instead of functional parts. Therefore, non-functionalized photocurable polymer products formed with 3D printers have deficiencies in terms of functionality and restrains the industrial application of polymers produced with 3D printing technology [4].

In order to improve not only mechanical properties but also thermal, electrical or magnetic properties in 3D photo-sensitive resins, many studies have been carried out by using different additives with stereolithographic method to date for use in sensors, actuators, MEMS applications [5,6]. For instance, Ikuta group [7] developed electrically conductive photocurable polymers for use as micro actuators. A voltage is applied between the beams to control the opening and closing functions using electrostatic force. Moreover, conductive or magnetically induced polymeric structures were also created by adding small amounts of metallic powders like $\mathrm{TiO}_{2}$, metal salts, ceramic particles, or carbon to a photocurable resin for making 3D structures more functional than pure structures [8-11]. 
For this study, in-situ thermal degradation by laser irradiation of cobalt $(\mathrm{Co})$, nickel $(\mathrm{Ni})$ and iron $(\mathrm{Fe})$ nitrates to form magnetically photocurable polymer structures were investigated by stereolithography technique. All experimental parameters were kept constant, except for the selected magnetic ( $\mathrm{Co}, \mathrm{Ni}$, $\mathrm{Fe})$ material used. Thus, understanding of the morphological, mechanical, thermal and magnetic behavior of each magnetic material in the photo-sensitive resin is critical and needs to be investigated by transmission/scanning electron microscopy (SEM/TEM), thermogravimetric analysis (TGA), differential calorimetry (DSC), vibrating sample magnetometer (VSM) and tensile test. In addition, the presence of agglomeration under magnetic effect during nanoparticle formation was also examined in this study.

\section{MATERIAL AND METHOD}

\subsection{Materials}

Nickel nitrate hexahydrate $\left(\mathrm{Ni}\left(\mathrm{NO}_{3}\right)_{2} \cdot 6 \mathrm{H}_{2} \mathrm{O}\right)$, cobalt (II) nitrate hexahydrate $\left(\mathrm{Co}\left(\mathrm{NO}_{3}\right)_{2} \cdot 6 \mathrm{H}_{2} \mathrm{O}\right)$ and iron (III) nitrate nonahydrate $\left(\mathrm{Fe}\left(\mathrm{NO}_{3}\right)_{3} .9 \mathrm{H}_{2} \mathrm{O}\right)$ were purchased from Kimetsan Company, Turkey, while sodium acrylate $\left(\mathrm{C}_{3} \mathrm{H}_{3} \mathrm{NaO}_{2}\right)$ was received from Sigma-Aldrich and used as received for the synthesis of magnetic $(\mathrm{Co}, \mathrm{Ni}, \mathrm{Fe})$ nitrate to magnetic acrylate. Photocurable resins consist of Ebecryl 7100 (Allnex) as acrylate based oligomer, pentaerythritol triacrylate (technical grade; Sigma-Aldrich) as arylate based monomer and Omnirad 819 (bis(2,4,6 trimethylbenzoyl) phenylphosphine oxide; IGM resins) as photo-initiator. Isopropyl alcohol $\left(\mathrm{C}_{3} \mathrm{H}_{8} \mathrm{O}\right.$; Isolab) was used to clean the remanent resin that did not form on the samples after printing.

\subsection{Magnetic Acrylate Preparation and Production of 3D Polymeric Structures}

Magnetic acrylate $(\mathrm{Co}, \mathrm{Ni}, \mathrm{Fe})$ was separately synthesized using previously reported methods, which are based on the first method developed by the Messori group [12]. Shortly, magnetic acrylate was synthesized by mixing magnetic nitrate and sodium acrylate at room temperature. According to their stoichiometric ratio, the exchange reaction happens rapidly, then magnetic acrylate-based solution was washed in water and twice in ethanol and centrifuged at 10.000rpm for 5 min to get a powder form of magnetic acrylate.

After obtaining magnetic acrylate, the photocurable resin was obtained by mixing $66 \%$ wt of Ebecryl 7100 with magnetic acrylate in ethanol solution and $32.75 \%$ wt of PETIA with $0.25 \%$ wt. of Omnirad 819 for 12 hours. $1 \mathrm{wt} \%$ magnetic ( $\mathrm{Co}, \mathrm{Ni}$, or $\mathrm{Fe})$ acrylate was added in each photocurable resin formulation for comparison. Ethanol, which provides easy dispersion of magnetic acrylate in the resin, was then evaporated by vacuuming at room temperature. Figure 1 shows how the laser irradiation of magnetic nanoparticles embedded polymeric structures after laser source is activated.

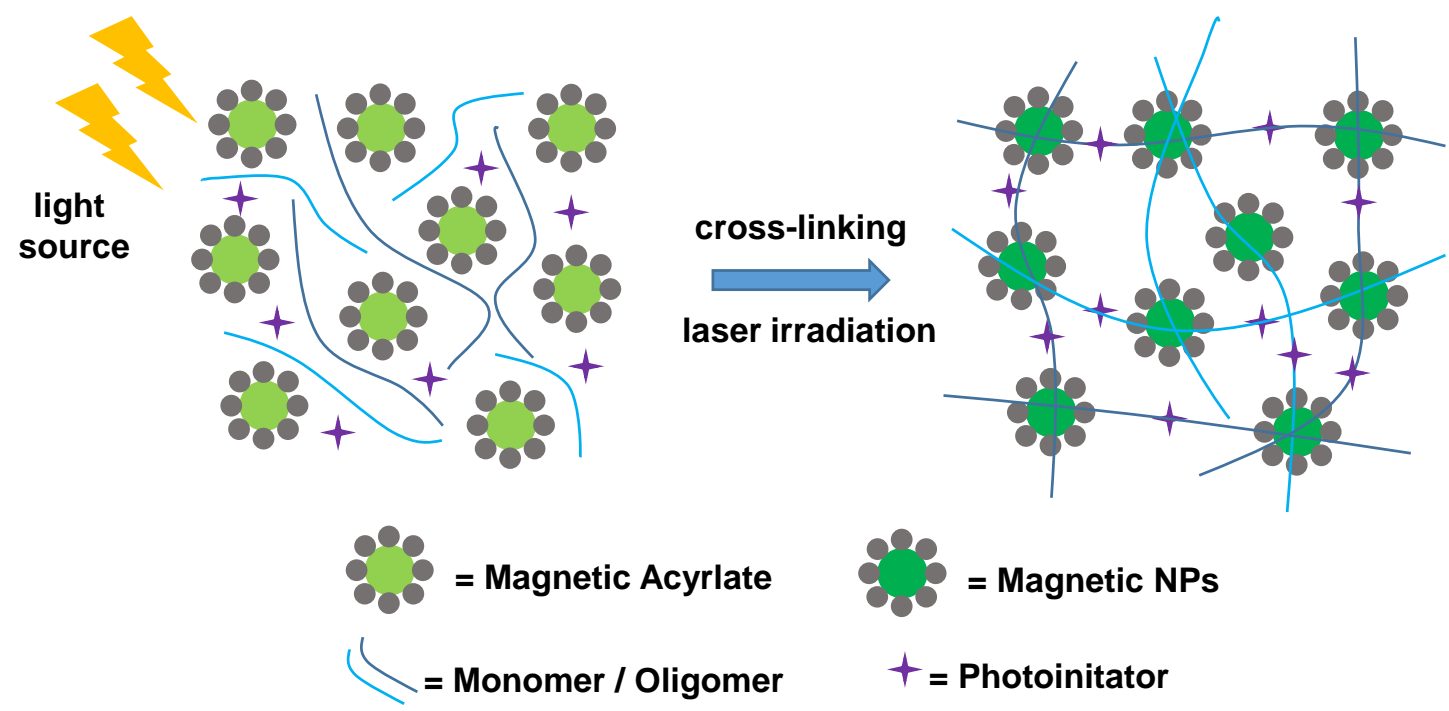

Figure 1. Schematic view of laser irradiation of magnetic nanoparticles embedded polymeric structures 
For processing the photo-curable formulations, a Form 1+ inverted SLA printer (Formlabs Inc., Somerville, MA, USA) was used with a $100 \mu \mathrm{m}$ layer thickness. The specimens were designed in SolidWorks (Dassault Systems SolidWorks Corporation, Waltham, MA, USA) and the CAD model was then converted into an STL file for printing. The printed samples were scaled in accordance with ASTM standards. The specimens were produced as shown in Figure 2a with stacking directions perpendicular to the specimen thickness, and then are used for analyses of structural, thermal, and magnetic properties. It is also seen in Figure $2 b$ that the reaction of magnetic ions reduction and radical polymerization occurred at the same time during photopolymerization which finally cause both a uniform composite formation and increasing the effectiveness of filler-polymer resin interface interactions. After the printing process, the samples were kept in an isopropyl alcohol (IPA) bath for 10 minutes and were dried then post-cured at $90{ }^{\circ} \mathrm{C}$ for 1 hour to make them ready for analysis.

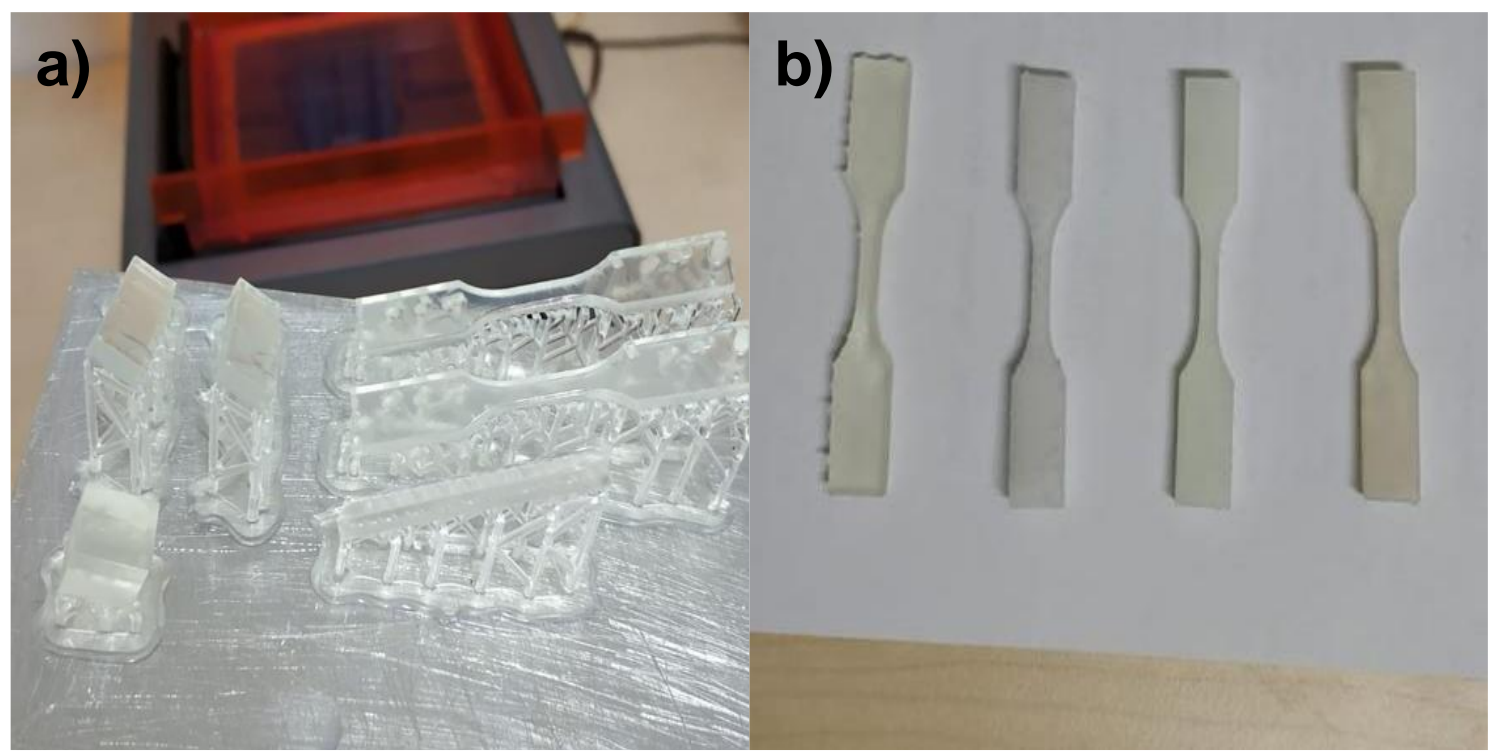

Figure 2. (a) Printed 3D samples and (b) pure, $\mathrm{Co}, \mathrm{Ni}$ and Fe containing 3D printed tensile test samples, respectively.

\subsection{Characterization Processes}

SEM (Scanning Electron Microscope) imaging of 3D printed polymer structures containing iron, nickel, and cobalt was performed using FEI Quanta FEG 250. Because of the insulating properties of the polymer, SEM was operated under low vacuum and $10 \mathrm{kV}$ conditions. Apart from SEM imaging, 200 kV JEOL JEM 2100 model TEM imaging integrated with TEM Oxford 80T EDS detector was used to determine particle morphology and point elemental mapping, respectively. The tensile test for each set of samples was carried out in a Zwick / Roell Universal tensile device in accordance with ASTM D638 standards. The stress-strain graphs obtained by pulling at a speed of $1 \mathrm{~mm} / \mathrm{min}$ using a $1 \mathrm{kN}$ load cell. Elasticity modulus, elongation at rupture and tensile strengths have been calculated and compared with each other. Thermogravimetric (TGA) analysis was carried out by a Perkin Elmer TGA 8000 under nitrogen (N2) gas environment at a heating rate of $10{ }^{\circ} \mathrm{C} / \mathrm{min}$ from $30{ }^{\circ} \mathrm{C}$ to $600{ }^{\circ} \mathrm{C}$ to determine the relative thermal stability of polymer - additive interactions. The thermal transition behavior of $3 \mathrm{D}$ printed polymer materials was also determined using Shimadzu DSC-60 Differential Scanning Calorimetry under $\mathrm{N}_{2}$ environment at a heating rate of $10^{\circ} \mathrm{C} / \mathrm{min}$ from $20^{\circ} \mathrm{C}$ to $300{ }^{\circ} \mathrm{C}$. The magnetic characteristics of $\mathrm{Co}, \mathrm{Ni}$, and $\mathrm{Fe}$ added polymeric structures were measured in a field of $\pm 20 \mathrm{kOe}$ at room temperature using a vibrating sample magnetometer (Lake Shore 7407 Series VSM).

\section{EXPERIMENTAL RESULTS}

\subsection{Morphological investigation}

SEM images of 3D printed $\mathrm{Co}, \mathrm{Ni}$ and Fe containing polymeric are given in Figure 3. It was observed that nanoparticles were relatively agglomerated in the red circular regions. These agglomeration phenomena, which are seen from $10 \mu \mathrm{m}$, have caused the need to be visualized with TEM to be understood more clearly. 


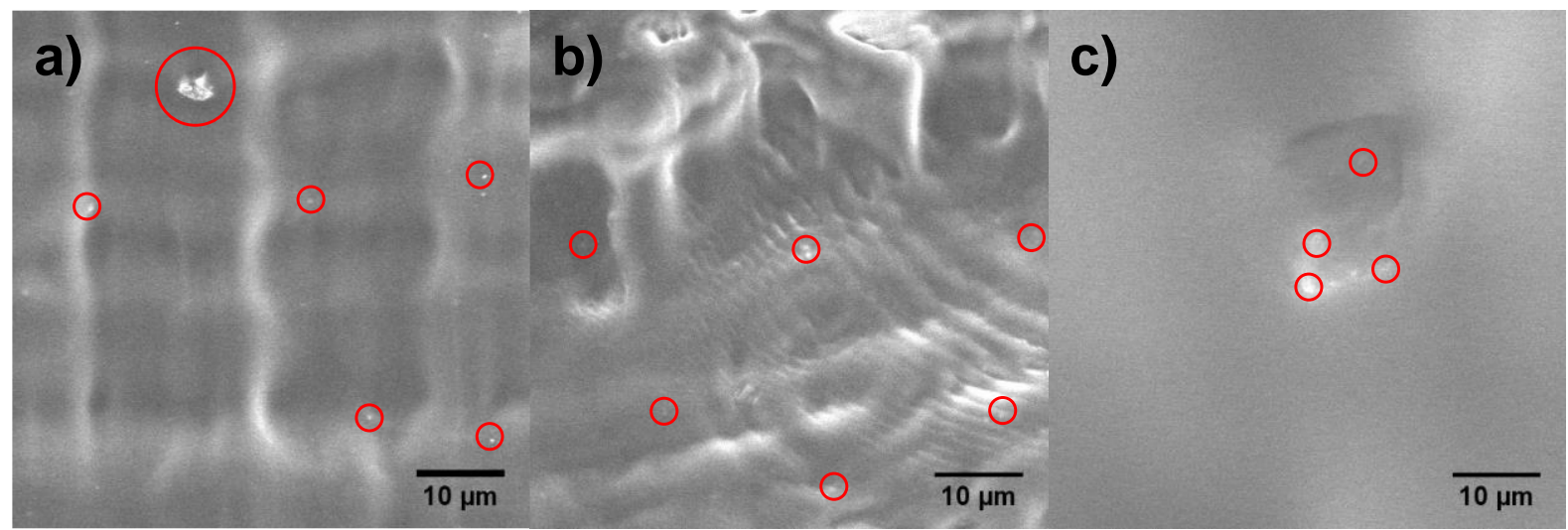

Figure 3. SEM images of printed 3D structures made of (a) cobalt, (b) nickel and (c) iron, respectively.

Figure 4 shows TEM images of 3D printed polymer structures. The particular nanoparticles were clearly visible in the polymer matrix as seen in Figure 3. The particles are about to spherical form except iron shows more irregular shape and it appears that the polymer diffuses well into the matrix. Average particle sizes of cobalt, nickel and iron are $23 \mathrm{~nm}, 60 \mathrm{~nm}$ and $47 \mathrm{~nm}$, respectively. A total of 30 particle sizes were measured from each image. The EDS point analysis of magnetic particles shows high crystallinity and the remaining amount is known as magnetic acrylate content that could not complete the thermal degradation during photo-polymerization.

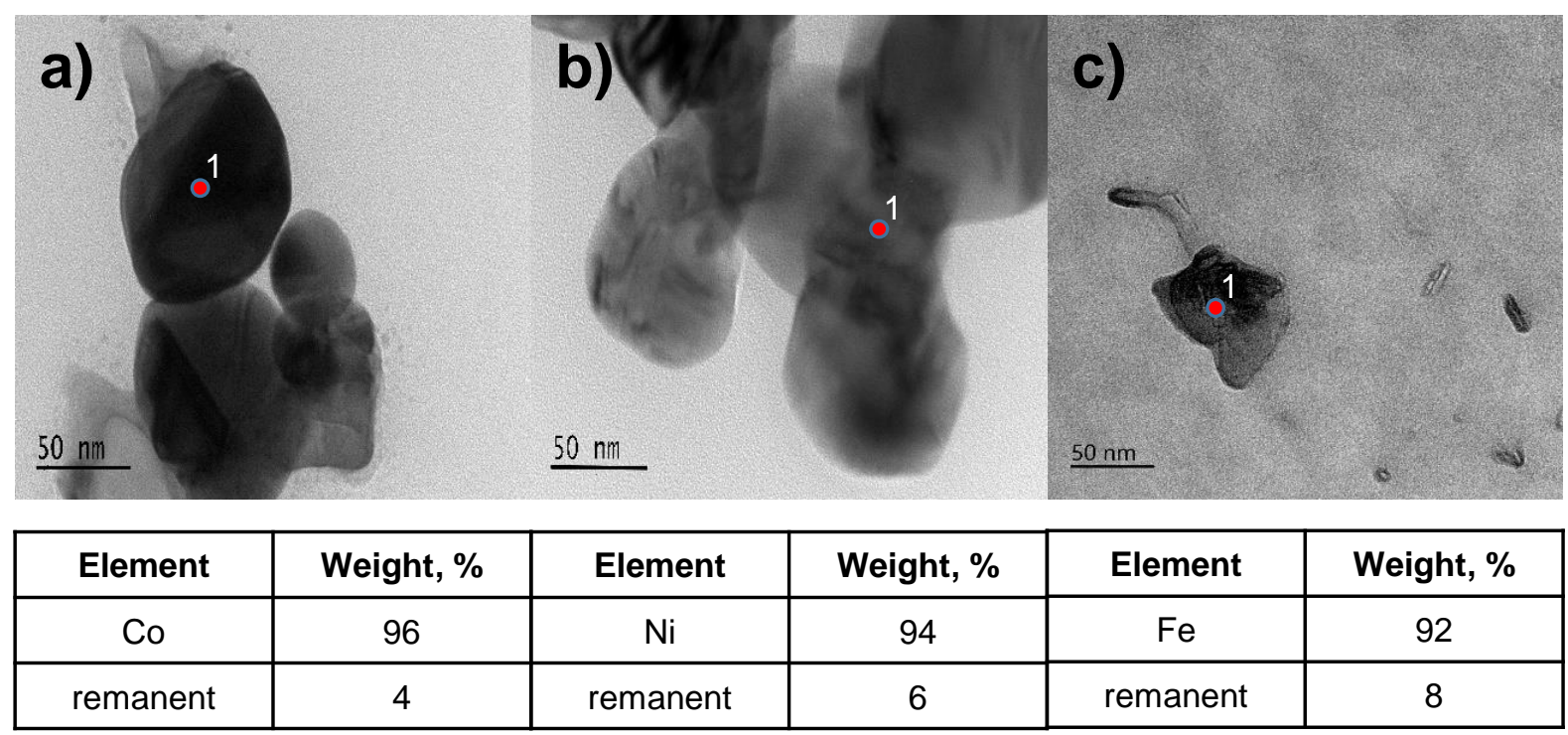

Figure 4. TEM images of printed 3D structures made of (a) cobalt, (b) nickel and (c) iron, respectively and their EDS point elemental analysis at below for each relative image

\subsection{Mechanical property results}

The stress-strain curves of 3D printed pure and magnetic added polymer structures are given in Figure 5. While the maximum tensile strength reached its highest value $(14 \mathrm{MPa})$ in pure polymer, it was observed that the $\mathrm{Co}, \mathrm{Ni}$ and $\mathrm{Fe}$ containing polymer samples are more brittle structure and a decrease in tensile strength from $8 \mathrm{MPa}$ to $5 \mathrm{MPa}$. Due to the load transfer phenomenon, samples behave as a brittle structure and also shows relatively low modulus of elasticity than pure polymeric structures. Furthermore, the percent elongation values of $\mathrm{Ni}$ including polymer shows approximately $5 \%$ strain value, showing relatively strong polymer-matrix interaction, rather than $\mathrm{Co}(2.3 \%)$ and $\mathrm{Fe}(2.6 \%)$. 


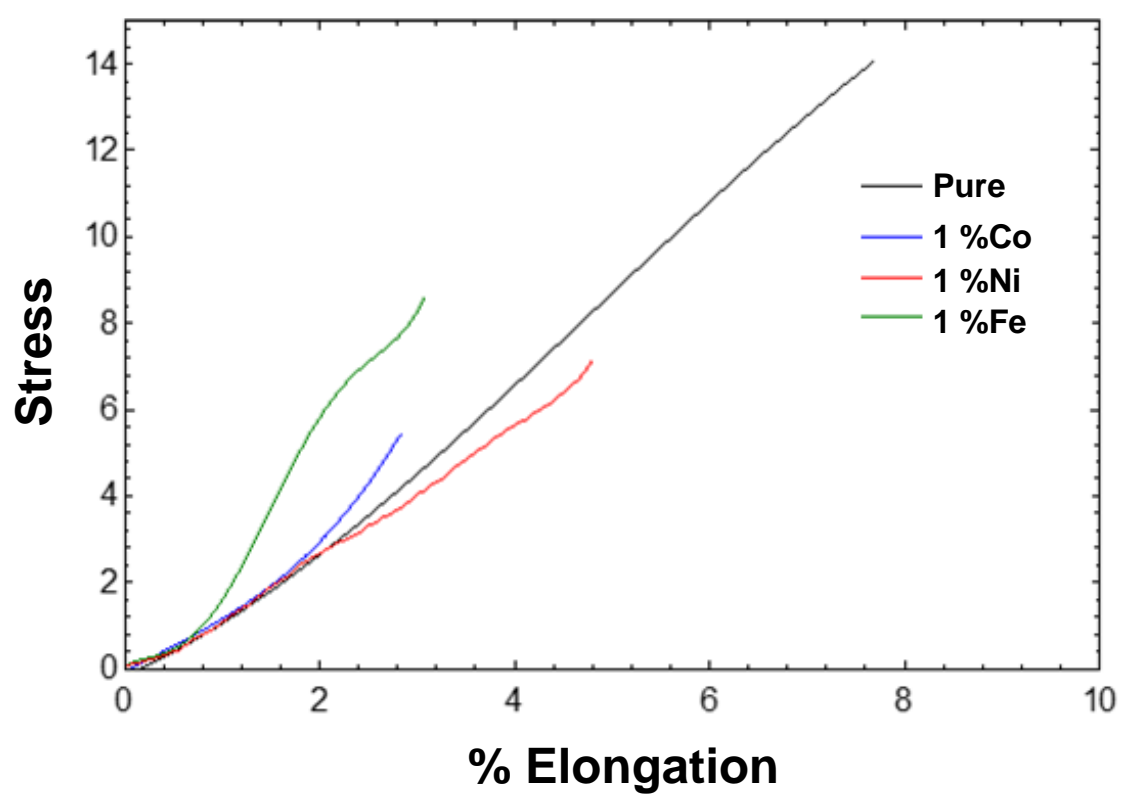

Figure 5. Stress-strain curve of 3D printed pure and magnetic structures

\subsection{Thermal property results}

TGA analysis of 3D printed samples are given in Figure 6. Thermal degradation of all samples happening between $300^{\circ} \mathrm{C}$ to $500{ }^{\circ} \mathrm{C}$ was likely because of the evaporation of organic species from the resin. However, the polymeric structures containing $\mathrm{Ni}$, $\mathrm{Co}$ and $\mathrm{Fe}$ compared to the pure polymeric structure showed that magnetic nanoparticles were not appreciably damaged during the heating ramp and the weight loss was mostly due to deterioration of the polymeric matrix.

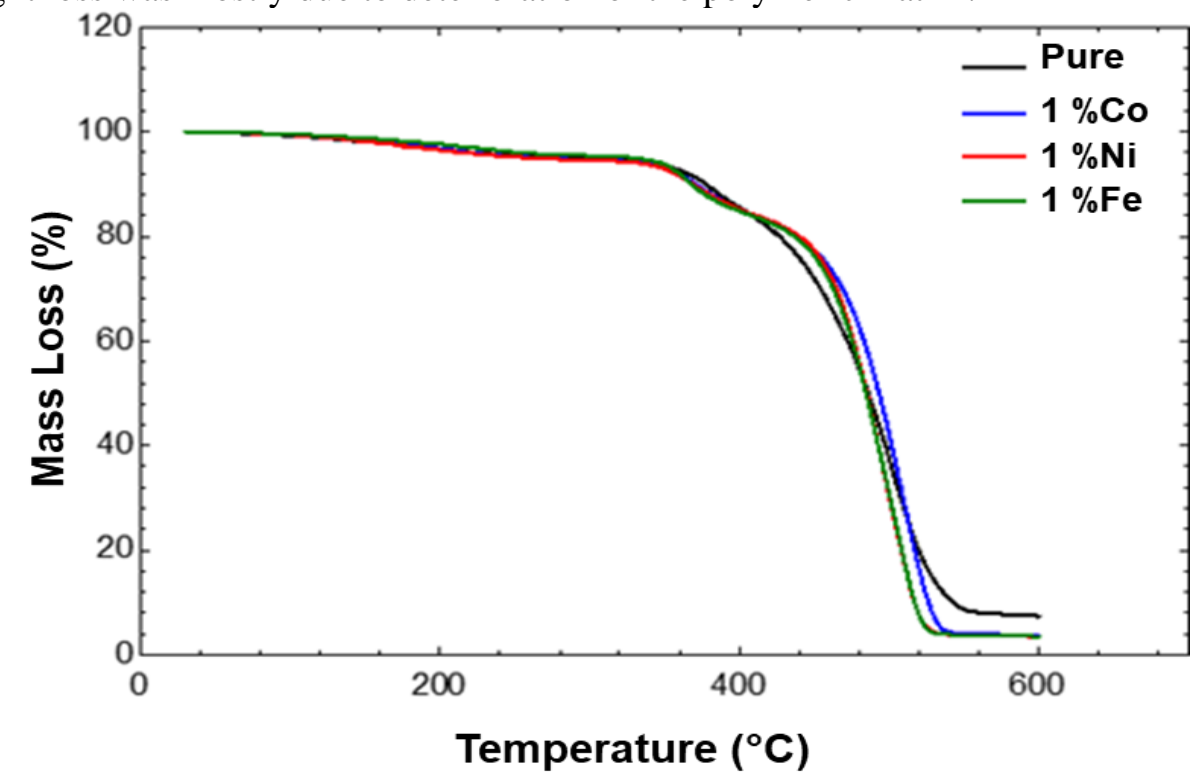

Figure 6. TGA analysis of printed 3D structures containing pure, $\mathrm{Co}, \mathrm{Ni}$ and $\mathrm{Fe}$.

Figure 7 show a broad glass transition region at $215^{\circ} \mathrm{C}$ for $\mathrm{Ni}$, at $225^{\circ} \mathrm{C}$ for $\mathrm{Co}$ or $\mathrm{Fe}$ containing samples and at $270^{\circ} \mathrm{C}$ for the pure polymeric structures. The glass transition region decreased when loading the resin with $\mathrm{Co}, \mathrm{Ni}$ and $\mathrm{Fe}$ nanoparticles. So, it can be said that magnetic containing polymeric structures decreased the thermomechanical bulk properties due to interfacial defects such as weak nanoparticle / resin bonding in the $3 \mathrm{D}$ polymeric structure. 


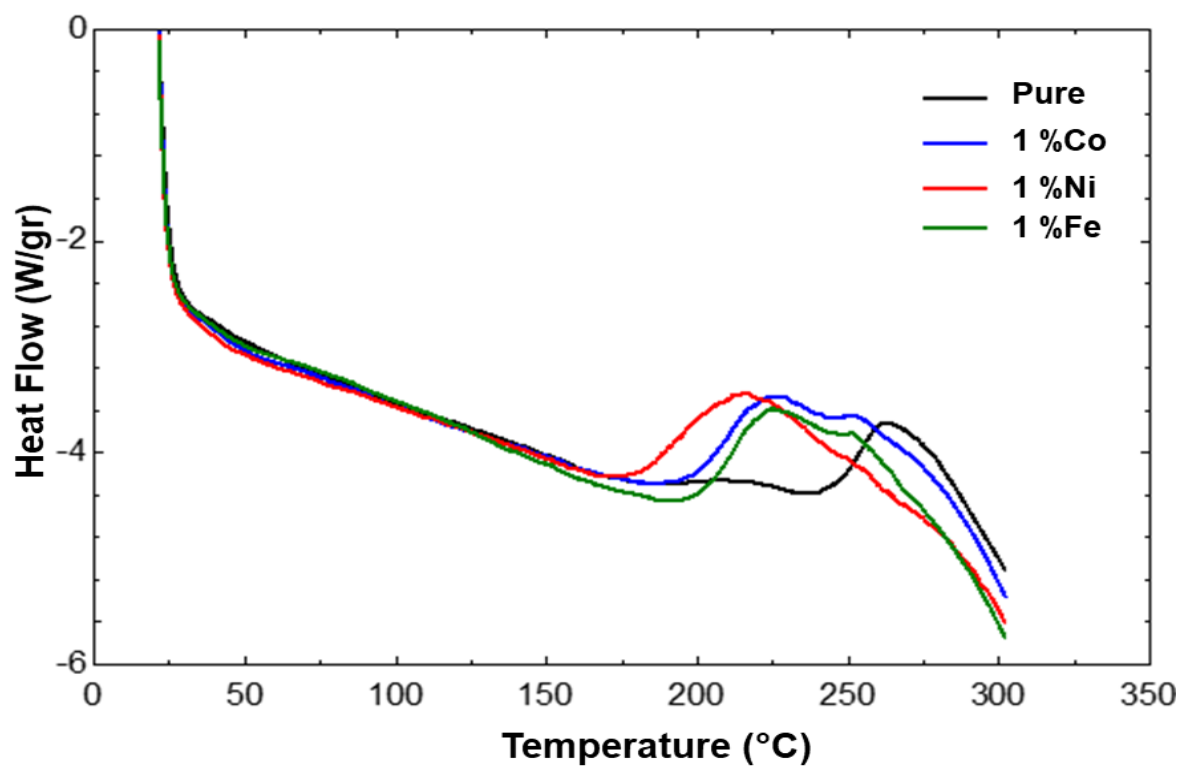

Figure 7. DSC analysis of printed 3D structures containing pure, Co, Ni and Fe.

\subsection{Magnetic Property Results}

Room temperature hysteresis loops of the $\mathrm{Fe}$, Co and Ni containing 3D polymeric structures are shown in Figure 8. Table 1 shows the saturation magnetization (Ms), remanent magnetization (Mr), and coercivity $(\mathrm{Hc})$ values derived from these curves. Saturation magnetization $\left(\mathrm{M}_{\mathrm{s}}\right)$ values of $\mathrm{Ni}, \mathrm{Co}$ and Fe containing polymeric structures were found to be $0.0145,0.0142$, and $0.0119 \mathrm{emu} / \mathrm{g}$, respectively.

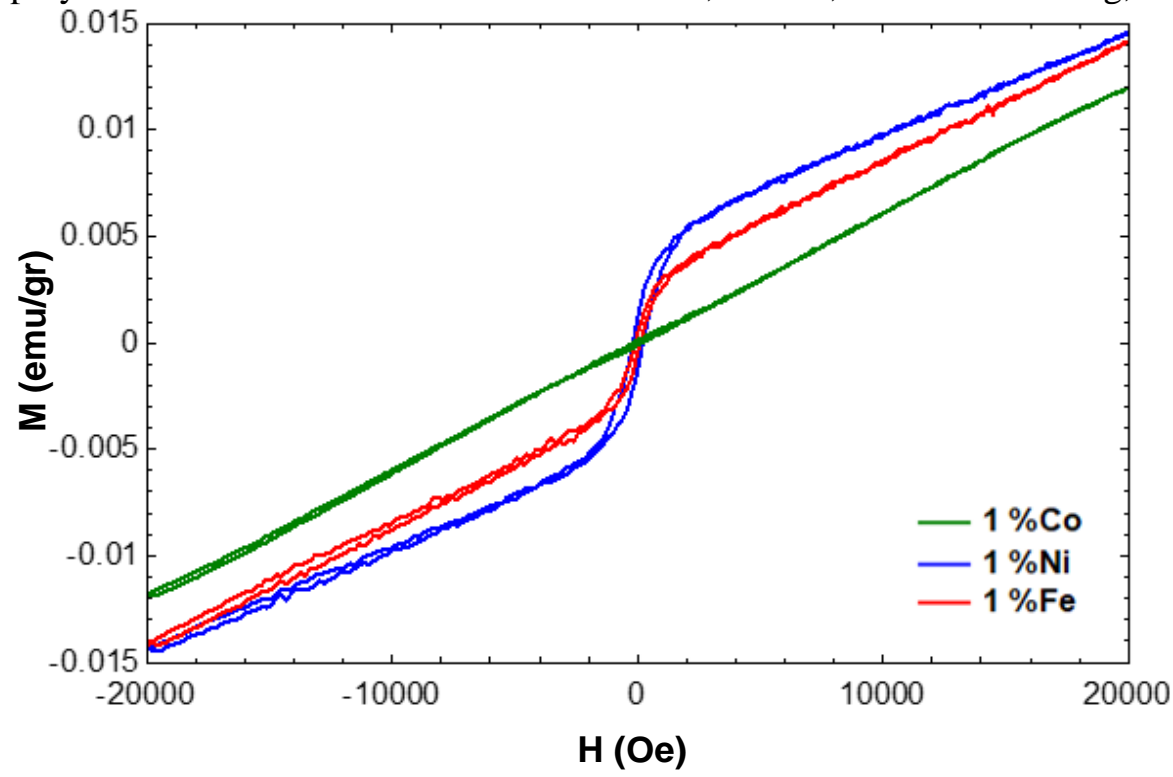

Figure 8. VSM analysis of printed 3D structures containing $\mathrm{Co}, \mathrm{Ni}$ and $\mathrm{Fe}$.

With increasing the average particle size of magnetic nanoparticles in 3D polymer matrix, the saturation magnetization (Ms), remanence (Mr), and coercivity ( $\mathrm{Hc}$ ) of magnetic nanoparticles added polymeric structures were raised, demonstrating the ferromagnetic behavior of all samples. Furthermore, the coercivity values range from 0.110 to 0.202 Oe, indicating that the magnetic moment responds coherently to an external magnetic field $\mathrm{H}$ and is dependent on particle size.

Table 1. Magnetic properties of printed 3D structures containing $\mathrm{Co}$, Ni and $\mathrm{Fe}$

\begin{tabular}{cccc}
\hline \hline Sample & $\mathbf{M}_{\mathbf{s}}(\mathbf{e m u} / \mathbf{g})$ & $\mathbf{M}_{\mathbf{r}}(\mathbf{e m u} / \mathbf{g})$ & $\mathbf{H}_{\mathbf{c}}(\mathbf{O e})$ \\
\hline \hline $\mathrm{Ni}$ & 0,0145 & 0,001220 & 0,202 \\
$\mathrm{Fe}$ & 0,0142 & 0,000460 & 0,164 \\
$\mathrm{Co}$ & 0,0119 & 0,000102 & 0,110
\end{tabular}




\section{CONCLUSION}

This study demonstrates what the SLA process can do to a solid matrix by reducing magnetic salts to magnetic nanoparticles while simultaneously polymerizing liquid monomers. Thanks to the selection of cobalt, nickel and iron salts with reactive counterions such as acrylates, the resulting nanocomposite material is homogeneous and free of extractable byproducts. Indeed, some of the reactive versus ionic polymer structures can stabilize the interfacial interactions of nanoparticles and polymers. As a result of the above analysis, it is clearly seen that the main factor driving is the matrix nanoparticle bonding and average particle dimension in terms of their mechanical and thermal stability. By comparing nickel with cobalt and iron nanoparticles, nickel with higher average particle size indicated slightly higher magnetic properties, better nanoparticle-matrix interaction as well as relatively better thermal and mechanical stability in 3D magnetic polymeric structures.

\section{REFERENCES}

1. Bártolo, P.J., "Stereolithography: materials, processes and applications", Springer, New York, 2011.

2. Lantean, S., Barrera, G., Pirri, C.F., Tiberto, P., Sangermano, M., Roppolo, I., Rizza, G., "3D Printing of Magnetoresponsive Polymeric Materials with Tunable Mechanical and Magnetic Properties by Digital Light Processing", Advanced Materials Technologies, Volume 4, Issue 11, Article Number 1900505, 2019.

3. Martin, J.J., Fiore, B.E., Erb, R.M., "Designing bioinspired composite reinforcement architectures via 3D magnetic printing", Nature Communications, Volume 6, Article Number 8641, 2015.

4. Gurr, M., Hofmann, D., Ehm, M., Thomann, Y., Kübler, R., Mülhaupt, R., “Acrylic nanocomposite resins for use in stereolithography and structural light modulation based rapid prototyping and rapid manufacturing technologies", Advanced Functional Materials, Volume 18, Issue 16, Pages 2390-2397, 2008.

5. Weng, Z., Zhou, Y., Lin, W., Senthil, T., Wu, L., "Structure-property relationship of nano enhanced stereolithography resin for desktop SLA 3D printer", Composites Part A: Applied Science and Manufacturing, Volume 88, Pages 234-242, 2016.

6. Leigh, S.J., Purssell, C.P., Bowen, J., Hutchins, D.A., Covington, J.A., Billson, D.R., “A miniature flow sensor fabricated by micro-stereolithography employing a magnetite/acrylic nanocomposite resin", Sensors Actuators A: Physical, Volume 168, Issue 1, Pages 66-71, 2011.

7. Yasui, M., Ikuta, K., "Modeling and measurement of curing properties of photocurable polymer containing magnetic particles and microcapsules", Microsystems \& Nanoengineering, Volume 3, Article Number 17035, 2017.

8. Sandoval, J.H., Wicker, R.B., "Functionalizing stereolithography resins: effects of dispersed multi-walled carbon nanotubes on physical properties", Rapid Prototyping Journal, Volume 12, Issue 5, Pages 292-303, 2006.

9. Fantino, E., Chiappone, A., Roppolo, I., Manfredi, D., Bongiovanni, R., Pirri, C.F., Calignano, F., "3D printing of conductive complex structures with in situ generation of silver nanoparticles", Advanced Materials, Volume 28, Issue 19, Pages 3712-3717, 2016.

10. Sandoval, J.H., Soto, K.F., Murr, L.E., Wicker, R.B., "Nanotailoring photocrosslinkable epoxy resins with multi-walled carbon nanotubes for stereolithography layered manufacturing", Journal of Materials Science, Volume 42, Issue 1, Pages 156-165, 2007.

11. Aktitiz, İ., Aydın, K, Topçu, A., "Characterization of $\mathrm{TiO}_{2}$ Nanoparticle-Reinforced Polymer Nanocomposite Materials Printed by Stereolithography Method", Journal of Materials Engineering and Performance, Just Accepted, 2021.

12.Taormina, G., Sciancalepore, C., Bondioli, F., Messori, M., "Special Resins for Stereolithography: In Situ Generation of Silver Nanoparticles", Polymers, Volume 10, Issue 2, Article Number 212, 2018. 